\title{
Analysis on Flow Patterns of Two-phase Flow and Lifting Capacity in Two-stage Bubble Pump with Lithium Bromide Solution
}

\author{
Bingbing Liu \\ Institute of Refrigeration \& Cryogenics Engineering, \\ Dalian Maritime University, \\ Dalian, 116026, China \\ e-mail:bf_228@126.com
}

\section{Hongtao Gao*}

Institute of Refrigeration \& Cryogenics Engineering, Dalian Maritime University,

Dalian, 116026, China

e-mail:gaohongtao@dlmu.edu.cn

\author{
Long Meng \\ Institute of Refrigeration \& Cryogenics Engineering, \\ Dalian Maritime University \\ Dalian, 116026, China \\ e-mail:935821181.qq.com
}

\begin{abstract}
Bubble pump was proposed to replace the traditional mechanical solution pump in the lithium bromide absorption chiller, for its advantageous feature that can be driven by industrial waste heat or solar energy or other lowgrade energy. It is found that different flow patterns in ascending pipe have large relations with the performance of bubble pump. In this paper, effects of flow patterns of twophase flow on lifting capacity are analyzed in two-stage bubble pump with lithium bromide solution. Different flow patterns of two-phase flows in ascending pipe are observed by high-speed camera. Velocities of the liquid-phase in different flow patterns in vertical pipe with lithium bromide solution are measured. The gas production of the system and the lifting capacity of bubble pump under different flow patterns are obtained by calculation. The changes of concentration of working fluid in different flow patterns are also calculated. The main flow patterns observed include bubble flow, slug flow, churn flow and annular flow at different concentrations of lithium bromide solution. The comparison of different concentrations of lithium bromide shows a tendency that the corresponding velocity for the same pattern with low concentration solution is little greater than that with high concentration.
\end{abstract}

Keywords-bubble pump; flow pattern; lifting capacity; gas production; flow rate

\section{INTRODUCTION}

In pump-free lithium bromide absorption refrigeration system, bubble pump replaces the traditional mechanical pump, not only can reduce the consumption of high-grade heat source greatly, but also can avoid the corrosive effects of mechanical pump by the working fluid, and can improve the reliability of the entire refrigeration system. Bubble pump itself does not consume additional energy, since the characteristics that the boiling point of lithium bromide solution is much higher than water, bubble pump use heated lithium bromide to produce steam, mixed density decreases, the lift force produce by parallax of absorber surface formed lift the mixed fluid to gas-liquid separator, so that cycle the whole refrigeration system. Performance and efficiency of bubble pump is mainly determined by the amount of lifting lithium bromide solution, while the concentration of lithium bromide solution and two phase flow pattern have a decisive role on the amount of lift. Many scholars have done a lot of experiments to study bubble pump's performance ${ }^{[1-8]}$. White ${ }^{[1]}$ found that the bubble pump have the highest transport efficiency when the two-phase flow in the lift pipe are transiting from slug flow to massive flow in Einstein refrigeration cycle. Saravanan et al ${ }^{[2]}$ researched some aspects influencing the system performance, such as the amount of heat and the lifting height and the driving pressure and the changes in the concentration of the solution. Vcators and Bnnet ${ }^{[3]}$ used multi-tube bubble pump to increase the lifting capacity of working fluid, and they have the conclusion that the lifting capacity is only relate to input heating. Benhmidene et al ${ }^{[4-5]}$ pointed that the bubble pump have the highest operational efficiency in slug flow, and the diameter of lifting tube is the most important parameter which influence the flow pattern. Pfaff et al ${ }^{[6]}$ have a study on bubble pump for a waterlithium bromide vapor absorption refrigerator, they found that reducing the diameter or height of lifting tube, increasing heating power, increasing the driving hydrostatic head all can make the oscillation cycle of the bubble pump shorten. And some scholars have done lots of research in two-phase flow patterns in vertical tube ${ }^{[9-12]}$. Liu et al ${ }^{[9]}$ observed that the air-water two phase flow pattern in vertical tube was similar in different tubes. But Hong et al ${ }^{[10]}$ found different flow patterns and flow pattern conversion boundaries in different tubes.

From the current published literature, we can see that the working fluids which scholars mainly researched are air and water or ammonia solution etc. A little literature 
involves the two phase flow pattern of lithium bromide solution and the influence of physical properties of the working fluid on flow pattern.

In this paper, we observe different flow patterns by high-speed camera and research the effect of concentrations of lithium bromide on bubble pump performance in the first stage lift tube of two-stage bubble pump with lithium bromide solution. The bubble flow, slug flow, plug flow, churn flow, annular flow and elastic annular flow are found. And the lifting ability of different flow patterns is researched.

\section{EXPERIMENTAL SYSTEM AND METHOD}

Experimental system is shown in Fig .1. The experimental apparatus consists of two-stage bubble pump with lithium bromide solution systems, high-speed photography system and data acquisition system. Bubble pump mainly include generator, the gas-liquid separator, absorber, condenser, interconnecting tube and so on.

In this paper the working fluid is the lithium bromide solution and the concentration of the solution are $57.5 \%$, $53 \%$ and $45 \%$. The first stage lift tube of bubble pump is circular glass tube of $9.5 \mathrm{~mm}$ diameter, $1800 \mathrm{~W}$ heating power is kept constant and the immersion height is $450 \mathrm{~mm}$. In the experiment the Phantom®v310 high speed digital camera is used to observe the flow conditions in the tube in different heating time, and to record the different flow patterns. Then we research the flow pattern changes of gas-liquid two-phase flow with different concentrations lithium bromide solution. And the Gas-liquid two-phase flow parameters, such as temperature and pressure, are measured.

Second-stage gas-liquid

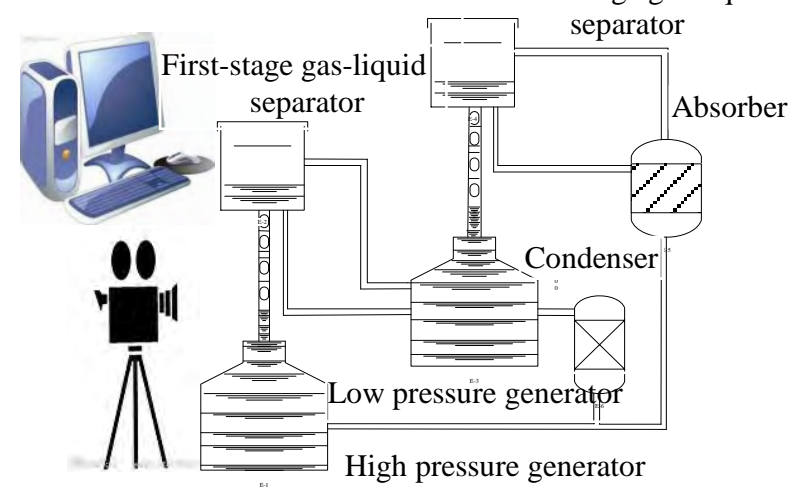

Figure 1. The sketch of experiment setup

\section{EXPERIMENTAL RESULTS AND ANALYSIS}

\section{A. Flow patterns and velocities of the gas-liquid two- phase flow}

In the experiments, two-stage bubble pump cycle is performed by continually heating the lithium bromide solution to observe the flow pattern changes during the working process. As shown in Tab. I, we observed various flow patterns that include typical slug flow, plug flow, churn flow and annular flow.

Two-phase flow patterns are related to the physical properties of the working fluid such as density, viscosity, surface tension, etc. So lithium bromide solution with different concentrations leads to different two-phase flow patterns. The density, viscosity, surface tension of the
$57.5 \%$ lithium bromide solution is higher than the $53 \%$ and $45 \%$ lithium bromide solution. During the experiment, the diversification of flow pattern occurred. Slug flow pattern could not found in the $53 \%$ and $45 \%$ lithium bromide solution. It is found that the maximum lifting efficiency occurred during slug flow pattern in lots of research literature. It is also verified by our experimental research, such as the slug flow, observed in $57.5 \%$ lithium bromide solution, is of the highest lifting efficiency in all flow patterns.

\section{TABLE I. THE FLOW LOW PATTERNS AND SPEEDS OF DIFFERENT FLOW PATTERNS}

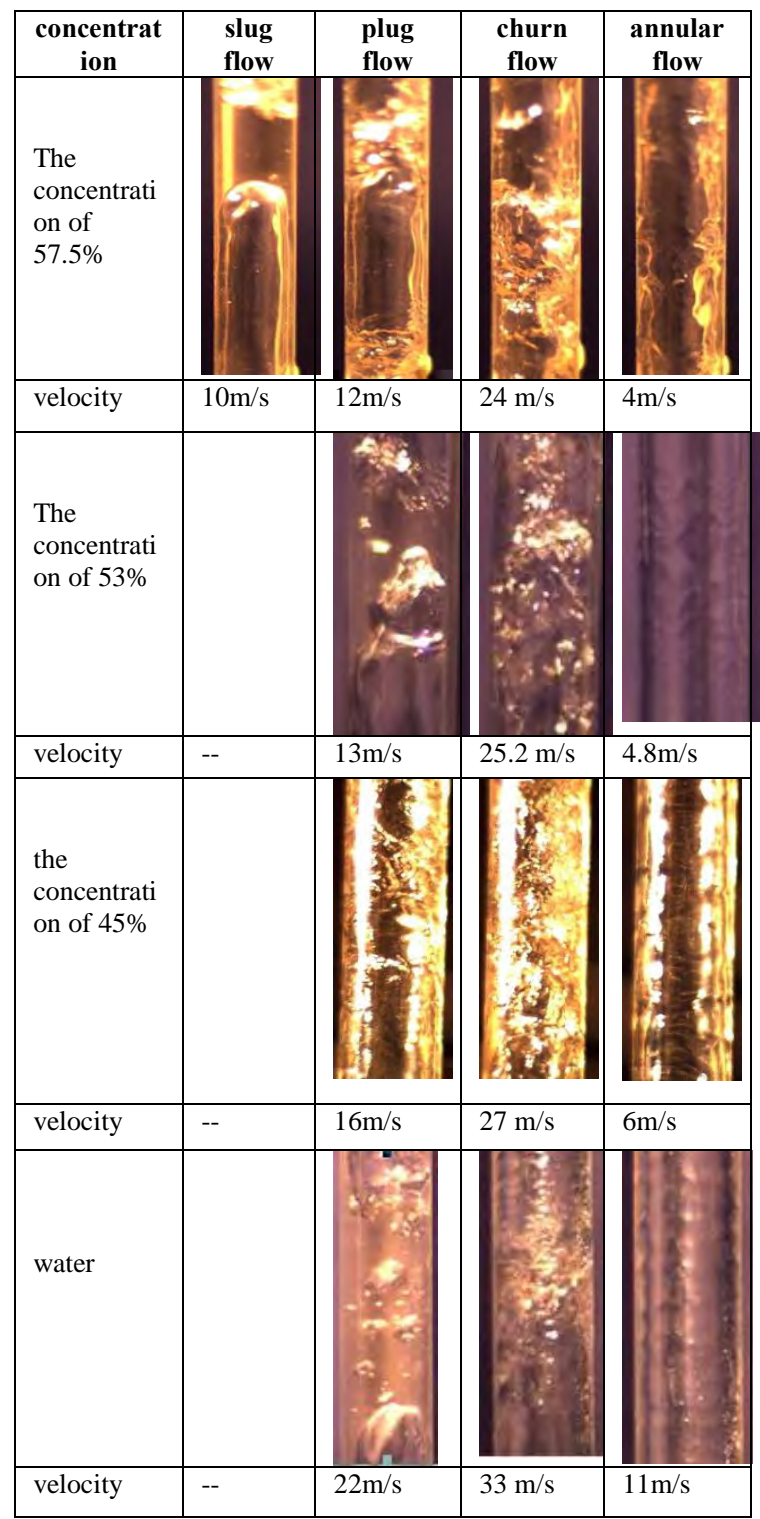

The screen resolution and the shooting rate are set to $1280 \times 800$ and 3250 frames per second, respectively, during measuring the flow rate by High-speed camera. The top of the surface of the rise solution is selected as recording points to obtain the average speed of the solution rises by the bubble rising displacements and camera shooting frames. The above pictures and calculated data in the table 1show that churn flow is with the highest flow rates in all flow patterns. Slug flow is a little weaker than 
plug flow. Annular flow, liquid and gas have separated, liquid rises along the wall with the lowest speed. Compared the data of three concentrations it is found that at the same flow patterns conditions the lower lithium bromide solution concentration, the higher the flow rate of liquid.

\section{B. Gas production of the high pressure generator}

In the experiment, the high-pressure generator is a stainless steel cylinder which both the diameter and the height is $220 \mathrm{~mm}$, the wall thickness of the cylinder is $6 \mathrm{~mm}$. A heater is in the middle of the bottom. A part of the heat losses through the liquid and the tube wall, residual heat is used to generate vapor water from lithium bromide solution.

The lost heat by per unit length of the cylinder wall is:

$$
Q_{\text {lost }}=\frac{t_{1}-t_{2}}{\frac{1}{2 \pi \lambda_{1}} \ln \frac{d_{2}}{d_{1}}+\frac{1}{2 \pi \lambda_{2}} \ln \frac{d_{3}}{d_{2}}}
$$

Where $t_{1}$ is the saturation temperature of the generator center solution, $t_{2}$ is the room temperature. $\lambda_{1}$ is the thermal conductivity of lithium bromide solution, $\lambda_{2}$ is the thermal conductivity of stainless steel, $d_{1}$ is the radius of heating rod, $d_{2}$ is the radius of the cylinder inside wall, $d_{3}$ is the radius of the cylinder outside wall.

It can be obtained by above formula that the $57.5 \%$ lithium bromide solution lost heat $54.1 \mathrm{~W}$, the $53 \%$ lithium bromide solution lost heat $46.4 \mathrm{~W}$, the $45 \%$ lithium bromide solution lost heat $34 \mathrm{~W}$ during their generation processes.

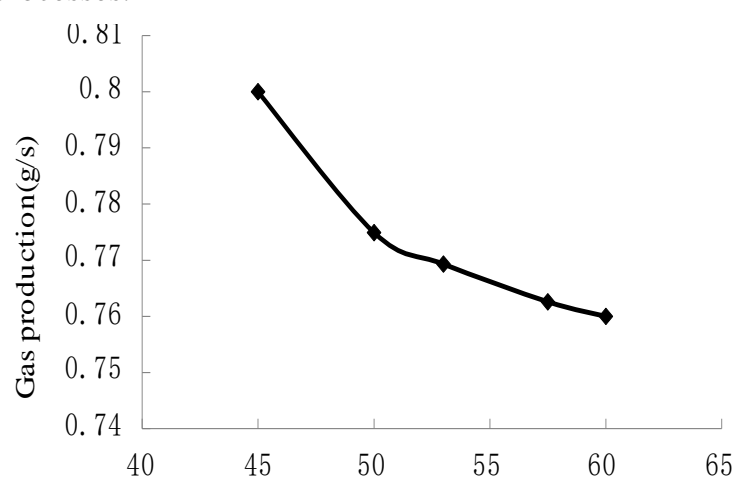

The concentration of $\mathrm{LiBr}$ solution(\%)

Figure 2. The gas production of different concentration solution

Fig .2 shows the gas production of different concentrations lithium bromide solution calculated by enthalpy difference method. As can be seen, the higher the lithium bromide solution concentration, the lower the gas production. But the reduced tendency of gas production becomes slow.

\section{The lifting amount of solution in different flow patterns}

Annular flow: When the flow pattern is annular flow, the average thickness $\delta$ of the liquid is about $0.0075 \mathrm{~mm}$ which is measured by handling picture data $57.5 \%$ lithium bromide solution. In $45 \%$ lithium bromide solution $\delta$ is $0.0043 \mathrm{~mm}$. In this case, the volume calculate formula of the lifting solution is:

$$
V_{L}=\pi\left(\frac{d}{2}\right)^{2} h_{L}-\pi\left(\frac{d-2 \delta}{2}\right)^{2} h_{L}
$$

Where $V_{L}$ is the volume of lifting solution, $d$ is the diameter of lifting tube, $h_{L}$ is the solution height. Set when the height of tube is $1 \mathrm{~cm}$, the volume of lifting solution is $0.00224 \mathrm{~cm}^{3}$. As we known, the gas production of $57.5 \%$ lithium bromide solution is $0.7626 \mathrm{~g} / \mathrm{s}$, at this point the water vapor density is $0.29345 \mathrm{~kg} / \mathrm{m}^{3}$. We obtained the volume of gas production per second $V_{G}$ is $2599 \mathrm{~cm}^{3}$. The diameter of tube is $9.5 \mathrm{~mm}$. By the formula:

$$
h_{G}=\frac{V_{G}}{\pi\left(\frac{d}{2}\right)^{2}}
$$

where $h_{G}$ is the height of gas production, we can get about $3668 \mathrm{~cm}$ gas production height per second. So the volume of the solution lifted by gas is $0.00224 * 3668=8.22 \mathrm{~cm}^{3}$ per second. The density of solution is $1625 \mathrm{~kg} / \mathrm{m}^{3}$. So in one second to lifting the quality of the solution is about $13.35 \mathrm{~g}$, The lifting quality of the $45 \%$ lithium bromide solution is about $12.52 \mathrm{~g}$ per second.

Plug flow: When the flow in tube becomes to be plug flow, 3.6 times of the columnar liquid appear every second in average. And the volume of each column is about 0.8 $\mathrm{cm}^{3}$, while the liquid thickness is equally $0.01 \mathrm{~mm}$. With the combination of equation (2) and (3), it can be obtained that the $57.5 \%$ lithium bromide solution is able to be lifted $22.64 \mathrm{~g}$ in one second, while the $45 \%$ lithium bromide solution can achieve $20.35 \mathrm{~g}$ per second.

Slug flow: For the $57.5 \%$ lithium bromide solution, the bullet slug flow arises 4.5 times every second. The average liquid thickness is $0.0175 \mathrm{~mm}$. The solution volume carried each time is $1.0 \mathrm{~cm}^{3}$. So, the lifting capacity is $34.26 \mathrm{~g} / \mathrm{s}$.

From the Tab. 2, it is known that the lifting capacity of slug flow is the best. Moreover, the fact that the velocity of slug flow is slower than plug flow indicates that the bubble pump works most effectively in slug flow. For annular flow, since the gas flow rate is too large, leading to the separation of gas and liquid, a small amount of the solution get lifted. 
TABLE II. LIFTING CAPACITY OF DIFFERENT FLOW PATTERNS

\begin{tabular}{llll}
\hline concentration & Slug flow & Plug flow & Annular flow \\
\hline $57.5 \%$ & $34.26 \mathrm{~g} / \mathrm{s}$ & $22.64 \mathrm{~g} / \mathrm{s}$ & $13.45 \mathrm{~g} / \mathrm{s}$ \\
$53 \%$ & -- & $20.86 \mathrm{~g} / \mathrm{s}$ & $12.83 \mathrm{~g} / \mathrm{s}$ \\
$45 \%$ & & $20.35 \mathrm{~g} / \mathrm{s}$ & $12.52 \mathrm{~g} / \mathrm{s}$
\end{tabular}

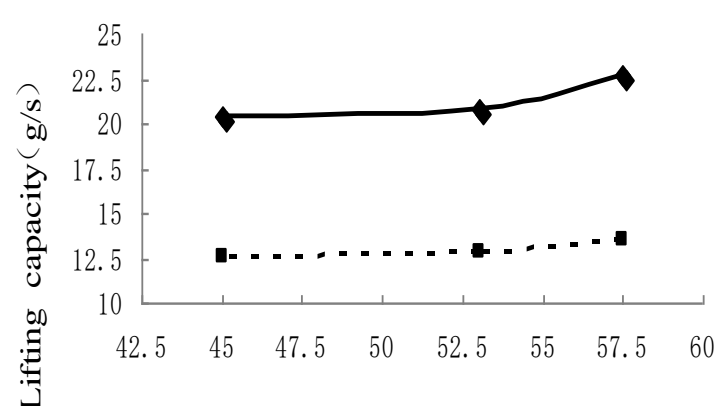

Concentration of solution $(\%)$

$\neg$ Plug flow - - - Annular flow

Figure 3. Lifting capacity of different flow patterns

\section{The concentration change of the solution induced by bubble pump}

Bubble pump can not only lift the solution, but also concentrate it during working. Knowing the rate of gas production and the lifting capacity of the solution, the concentrations of solution out of bubble pump can be calculated.

\section{TABLE III. CONCENTRATION OF SOLUTION AT THE OUTLET OF BUBBLE PUMP}

\begin{tabular}{ccccc}
\hline $\begin{array}{c}\text { concentr } \\
\text { ation }\end{array}$ & $\begin{array}{c}\text { Slug } \\
\text { flow }\end{array}$ & $\begin{array}{c}\text { Plug } \\
\text { flow }\end{array}$ & Annular flow & $\begin{array}{c}\text { Gas } \\
\text { production } \\
\text { range }\end{array}$ \\
\hline $57.5 \%$ & $58.77 \%$ & $59.4 \%$ & $60.74 \%$ & $1.2 \sim 3.2$ \\
$53 \%$ & -- & $54.6 \%$ & $56.1 \%$ & $1.3 \sim 3.1$ \\
$45 \%$ & -- & $46.8 \%$ & $47.9 \%$ & $1.7 \sim 2.9$ \\
\end{tabular}

The Tab. 3 displays the changes in concentration in different flow patterns. The primary $57.5 \%$ lithium bromide solution goes through bubble pump by slug flow, plug flow and annular flow, changed to $58.77 \%, 59.4 \%$ and $60.74 \%$, respectively. The mass fraction difference between primary solution and concentrated solution can be called deflated range. For the experimental apparatus in the paper, the deflated range is 1.2 to 3.2 .

It can be seen that the concentration of the solution after second ascending tube can reach more than $60 \%$, which is powerful enough to absorb the refrigerant without additional concentration of the solution. When annular flow appears, after the second lifting, the concentration can go up to $63 \%$.

\section{CONCLUSIONS}

In this paper a high-speed video camera is used to observe the flow status and to measure the velocity of liquid phase solution in different flow patterns. Effects of flow patterns of two-phase flow on lifting capacity are studied in two-stage bubble pump with lithium bromide solution. The gas production, the lifting capacity of bubble pump and the changes of concentration of working fluid in different flow patterns are obtained by calculation.

1) In the $57.5 \%$ lithium bromide solution bubble pump, we found the bubble flow, slug flow, plug flow, churn flow and annular flow. But in the 53\% and $45 \%$ lithium bromide solution bubble pump, slug flow was not found.

2) The velocities of the liquid phase in bubble pump are various in different flow patterns. The velocity of churn flow is the highest one. At the same conditions of flow patterns the lower the lithium bromide solution concentration, the higher the velocities.

3) The higher primary lithium bromide concentration, the lower gas production, and the stronger lifting capacity.

4) The slug flow show the best lifting capacity, and the annular flow the worst. But the solution concentration degree of annular flow is the highest.

\section{ACKNOWLEDGMENT}

The authors are grateful for the financial support from National Natural Science Foundation of China (No.50976015) and Liaoning S\&T project (No.2010224002) to this project.

\section{REFERENCES}

[1] White S. Bubble Pump Design and Performance [D].Atlanta: Georgia Institute of Technology, 2001

[2] Saravanan R, Maiya MP. Experimental Analysis of A Bubble Pump Operated $\mathrm{H}_{2} \mathrm{O}$-LiBr Vapour Absorption Cooler [J].Applied Thermal Engineering, 2003, 23: 2383-2397.

[3] Vicators G, Bennett A. Multiple lift tube pimps boost refrigeration capacity in absorption plants [J]. Journal of Energy in Southern Africa, 2007, 18 (3): 49-57.

[4] Benhmidene A, Chaouachi B, Gabsi S, Bourouis M. Modelling of heat flux received by a bubble pump of absorption-diffusion refrigeration cycles [J]. Heat Mass Transfer, 2011, 47(11):13411347.

[5] Benhmidene A, Chaouachi B, Gabsi S. A Review of Bubble Pump Technologies [J]. Journal of Applied Sciences, 2010, 10(16):1806-1813.

[6] Pfaff M, Sarvanan R, Maiya M P. Studies on bubble pump for a water-lithium bromide vapor absorption refrigerator $[\mathrm{J}]$. International Journal of Refrigeration, 1998, 21(6):452-462.

[7] Zhao R, Liu D, Wu Y, Chen Y, Lu Y. The theoretical and experimental research on performance of bubble pump with different lift height [J].Journal of Refrigeration, 2014, 35(4):78-83.

[8] Xue X, Liu D, Wang R. Analysis of the performance of the bubble pump in pump-free lithium bromide absorption refrigeration system [J].Cryogenics and Superconductivity, 2008, 36 (8): 50-53. Zhao R, Liu D, Wu Y, Chen Y, Lu Y. The theoretical and experimental research on performance of bubble pump with different lift height [J].Journal of Refrigeration, 2014, 35(4):78-83.

[9] Liu X, Li Z, Wu Y, Lv J. Effect of tube size on flow pattern of airwater two-phase flow in vertical tubes [J].Chinese Journal of Hydrodynamics, 2012, 27(5): 531-536.

[10] Hong W, Zhang G, Xiao F. Study on Flow Pattern and Transform Boundaries of Gas-Liquid Flow in Small vertical Upward Channel [J]. Journal Of Northeast Dianli University, 2014, 34(3): 26-29.

[11] Saisorn S, Wongwises S. An inspection of viscosity model for homogeneous two-phase flow pressure drop prediction in a horizontal circular micro-channel [J]. Internationa Communications in Heat and Mass Transfer, 2008, 35(7): 833-838. 
[12] Venkatesan M, Sarit K D, Balakrishnan AR. Effect of tube diameter on two-phase flow patterns in mini tubes $[\mathrm{J}]$. The
Canadian Journal of Chemical Engineering, 2010, 88(6): 936-944. 